\title{
Integrated Buck Boost Series Parallel Fly-Back Converter for Electronic Ballast and LED Drive Applications
}

\author{
Naga Pooja V, Pandu Kumar K, Sravan Kumar S L V, Lokeswararao K
}

\begin{abstract}
Integrated Buck Boost Series Parallel Fly-Back Converter (IBBSPFC) a single MOSFET Switch is used. This IBBSPFC can achieve high or low voltages by buck and boost process. The pass through a filter capacitances be able to be low thus to facilitate film capacitor can be used. Buck-boost converter can operate in Buck mode and Boost mode with continuous conduction mode by the inductor and capacitors. In this design, regulation and reliability of the converter improves when the capacitors are linked in series among the main winding of isolation transformer and the power transfer capability is improved by parallel connection of the isolation transformer with capacitor. By this IBBSPFC can increase and decrease of volt conversion without any transformer losses is obtained for different duty cycles. Therefore, this is beneficial for higher efficiency and reliability and the cost of the System can be reduced by using Fast recovery diodes, inductor and capacitors. By Conversion of $24 \mathrm{~V}$ input to $50 \mathrm{VOutput}$ in continuous conduction mode (CCM) under 100W output power is obtained.
\end{abstract}

Keywords: Integrated Buck Boost Series Parallel Fly- back Converter (IBBSPFC), Isolation Transformer, Continuous Conduction Mode (CCM), Open Loop Control, Buck-Boost Converter (BBC), Fly-back Converter (FC).

\section{INTRODUCTION}

Green power systems like Solar PV module and gas cells, are extensively used in industries \& mobile home areas designed for reducing of carbon emission. But, small amount of end power is their typical defect [1]. In grid-tied usage, DC input voltage of a converter have to be high abundant to infuse power to utility grid [2]. For switching mode power supplies (SMPS) it requires high efficiency and more power density with high switching frequency can reduce the size of the power converters.

In Isolated DC-DC Converter FC is considered with $\mathrm{BB}$ regulator. Whereas Buck and Boost converters are used in power converters to increase or decrease the voltage obtained at the output, Buck operates as step-down chopper and Boost operates as step-up chopper. In most of the PV cells we required to get more voltage. By using the buck-boost converter the voltage can be given to the inverter as it takes

Revised Version Manuscript Received on 10 September, 2019.

Naga Pooja V, PG Students,GNITS/EEE, Hyderabad, Telangana, India. (Email: nagapoojavuyyuru@gmail.com)

Pandu Kumar K, Asst. Prof. GNITS/EEE, Hyderabad, Telangana, India.

(Email: kuthurupandu@gmail.com)

Sravan Kumar S L V, Asst. Prof. GNITS/EEE, Hyderabad, Telangana, India.

(Email: Sravan_257@yahoo.co.in)

Lokeswararao K, Asst. Prof. School of Tech. GITAM, Bangalore Campus, Karnataka, India.

(Email: lokeshch85@gmail.com) low or high voltage [3]. Buck-Boost converter is a non isolated converter and whereas fly-back converter is a isolated regulator. In $\mathrm{BB}$ regulator the voltage at output side is more / low than the voltage at the supply side [4], applications are use in SMPS, [6] power amplifier and in battery power systems. The advantage of low operating duty cycle and higher output voltage. FC is taken as of the BB regulator as in $\mathrm{BBC}$ we use inductor coil $(\mathrm{L})$, so this inductor is splited to form as the isolated transformer. Fly-back converter has a particular propose to facilitate it is a not direct converter that it does not have a direct path between input and the output in any instant of operation [7]. Applications of fly-back transformer are it develops high voltage, can fix multiple outputs and has low switching stress [5]. IBBSPFC is connected in series parallel with the isolation transformer, with it is linked in parallel it increases the reliability when one transformer is faulted then other transformer can operate and when it is connected is series it improves connecting two transformers in the input side can operate with the high power transfer capability. These fly back transformers can be used in Aeronautical applications, electrical converters and inverters.

In this propose, of the integrated buck boost series parallel fly-back converter a single switch is used this can reduce switching stress with one switch. Buck boost inductor is used at the input side [8], whereas the fly-back inductor acts as isolated transformer it is connected across the capacitors, the capacitor used can be a film capacitor as it use a slight plastic film as the dielectric. These film capacitances are low-priced, steady and can with stand for large reactive power values. These film capacitors are used in electronic ballast, X-ray flashes and can be used in snubber capacitors [6].

It has Single power switch, three capacitors, one inductor, seven diodes and isolation transformer are the main components of this converter. The inductor is at the supply side so it has the voltage same as the supply voltage. The study and representation of the suggested converter or circuit configuration is shown in Section 2. Mathematical calculations are in Section 3. The MATLAB Simulated results are in part 4 and conclusions are shown in part 5. 


\section{CIRCUIT CONFIFURATION}

Circuit diagram of IBBSPFC has given in Fig. 1. With an Inductor, a single lever, two capacitors and six diodes at the input side with the isolation transformer; the output part of the isolation transformer is connected to $\mathrm{R}$ load with a Diode and the capacitor.

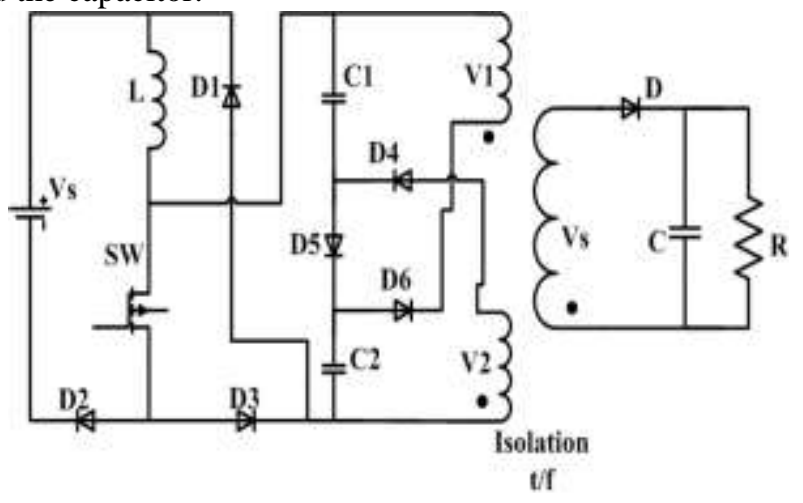

Fig. 1: Circuit Diagram of IBBSPFC

IBBSPFC circuit has four modes of operation. In $1^{\text {st }}$ the power transfer capability in the way like by mode lever is closed and coil of inductor gets charged and the current flows from Supply voltage to inductor, inductor through switch that flows through diode D2 back to supply voltage. Mode 1 circuit diagram is shown in fig. 1(a).

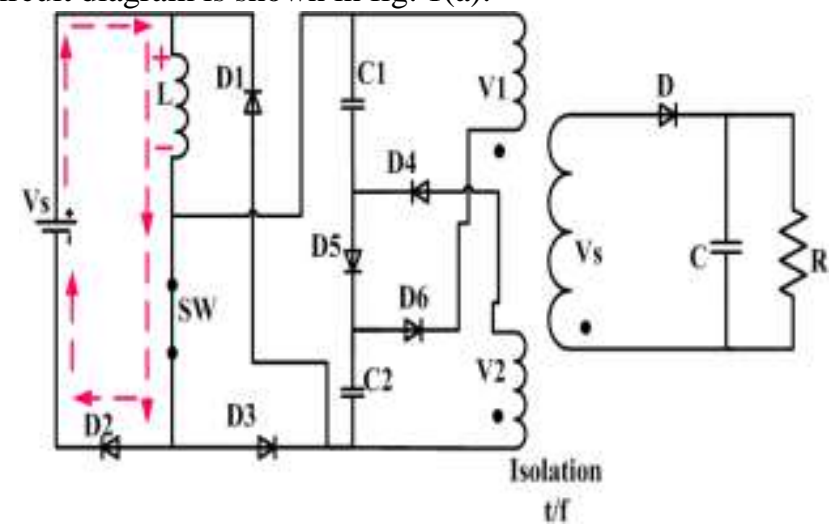

Fig. 1(a): Mode 1in the interval of $0<T<t 1$

In Mode 2 Switch is turned off inductor current gets discharged through capacitors so that the capacitors gets charged through $\mathrm{C} 1$ to D5, D5 to $\mathrm{C} 2, \mathrm{C} 2$ to D1 back to inductor so that it makes a closed loop. Mode 2 Circuit diagram is shown in fig. 1(b).

Mode 3 is shown in Fig. 1 (c), again lever is closed as mode 1 will repeat with capacitors gets discharged and the input side of the transformer will get energized [9].

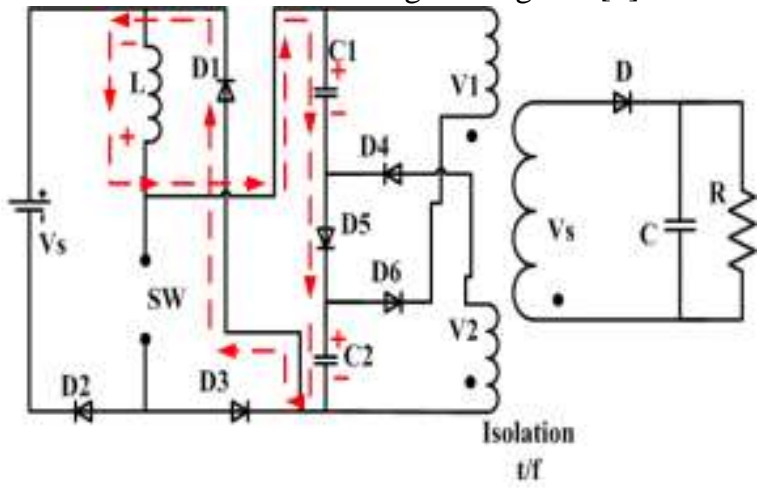

Fig. 1 (b): Mode 2 with limit $\mathrm{t}_{1}<\mathrm{T}<\mathrm{t}_{2}$

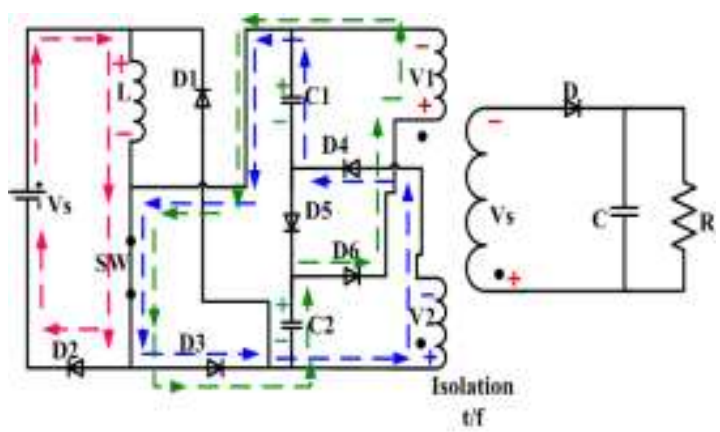

Fig. 1 (c): Mode 3 with limit $t_{2}<T<t_{3}$

In $4^{\text {th }}$ mode again mode 2 gets repeted with the capcitors gets charged from the input side of the transformer gets de-energised from the capacitors so that capacitors gets charged. When the transformer gets de-energised at the input side then due to the dot convention the output side of the transformer gets energised so that output voltage is high or low compared to the input voltage as it is buck boost converter.

After mode 4 again mode 3 and mode 4 gets repeated. Mode 4 is shown in fig. 1(d).

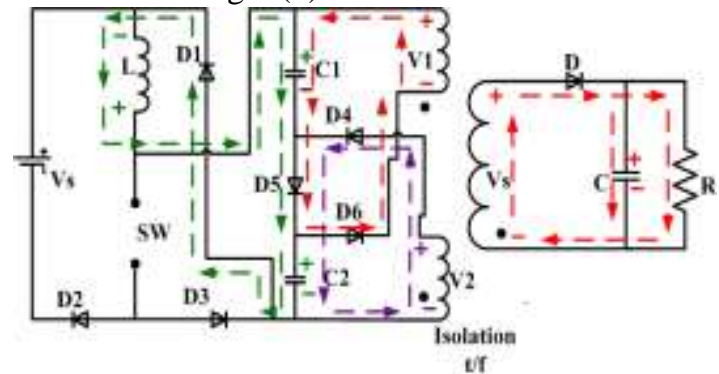

Fig. 1 (d): Mode 4 with $t_{3}<T<t_{4}$

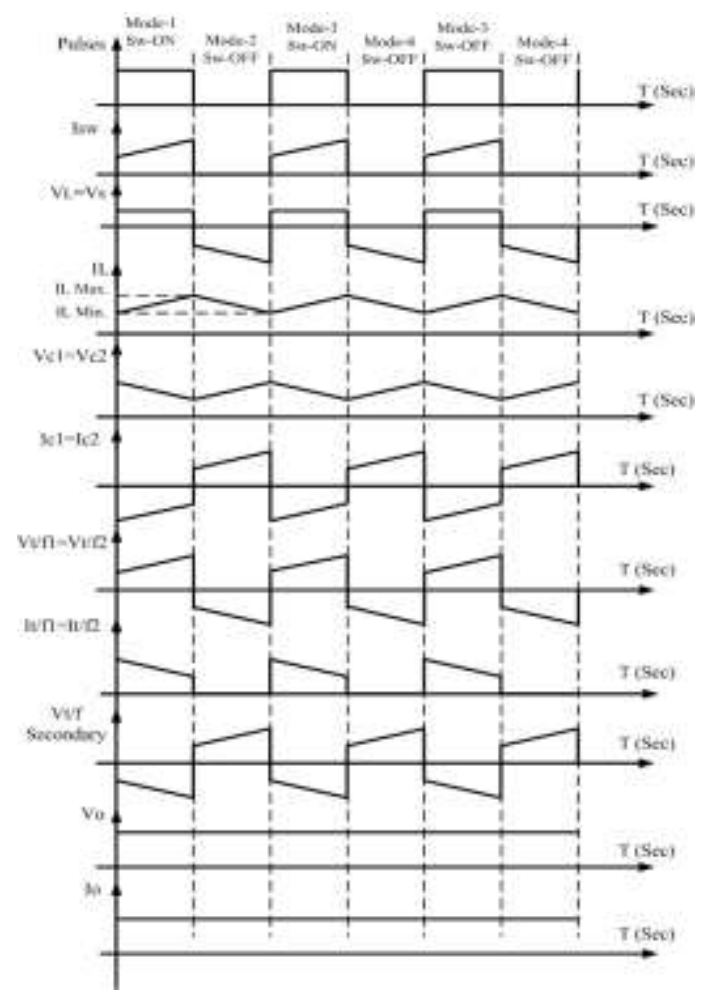

Fig. 2: Theoretical waveforms 
For these four modes of operation theoretical waveforms are shown in Fig. 2.

\section{MATHEMATICAL ANALYSIS}

Mathematical analysis for IBBSPFC is presented below for:

$V_{s}=24 V$

$V_{0}=50 \mathrm{~V}$

$I_{0}=2 A$

$f=100 \mathrm{KHz}$

$P_{0}=V_{0} I_{0}=50 X 2=100 \mathrm{~W}$

$P_{0}=P_{I N}$

$V_{0} I_{0}=V_{I N} I_{I N}$

$100=24 X I_{I N}$

$I_{I N}($ or $) I_{S}=4.166 A$

$V_{L}=V_{S}-V_{S W}-V_{D 2}$

$V_{L}=24-1.2-0.7$

$V_{L}=22.1 V$

$V_{L}=L \frac{d i}{d t}$

$22.1=L \frac{\Delta I}{D T}$

$22.1=L \frac{0.05}{0.00001}$ for $\Delta i=0.05 A$

$L=3.24 m H$

$C=\frac{I_{0} K}{f \Delta V} \quad$ Assume $\Delta \mathrm{V}=1.35$

$C=\frac{2 x 0.67}{10^{5} \times 1.35}=10 \mu F$

$i_{c}=c \frac{d v}{d t}$

$i_{c}=10 X 10^{-6} X \frac{1.35}{0.00001}$

$i_{c}=1.35 \mathrm{~A}$

$V_{0}=\frac{V_{S} K}{1-K}$

$50=\frac{24 K}{1-K}$

$K=0.675=67.5 \%$

$V_{0}=\frac{24 X 0.675}{1-0.675}$

$V_{0}=49.98$

$$
\begin{aligned}
& V_{C 1}=V_{C 2}=\frac{1}{2} V_{0} \\
& V_{C 1}=V_{C 2}=\frac{1}{2} X 49.94 \\
& V_{C 1}=V_{C 2}=24.99 \mathrm{~V} \\
& P_{T}=\left(1+\frac{1}{\eta}\right) P_{0} \\
& P_{T}=100 X 2=200 \mathrm{~W} \\
& P_{0}=100 \mathrm{~W} \\
& I_{t 1}=I_{1}=\frac{200-100}{50} \\
& I_{t 1}=I_{1}=2 \mathrm{~A}--------- \text { (10) } \\
& \eta=\frac{P_{0}}{P_{I N}}=\frac{49 \times 1.83}{24 X 4.16} \\
& \eta=89.81 \%
\end{aligned}
$$

\section{SIMULATION RESULTS}

MATLAB model simulated results for the system shown in fig. 3. Whereas fig. 4 and figure 5 with a Switch V and I waveforms, Figure 6 and 7 with Inductor voltage and current waveforms, Fig. 8 shows Capacitor voltages Vc1 \& Vc2, Fig. 9 shows capacitor currents Ic1 \& Ic2 wave forms, Fig. 10 shows Transformer primary voltage Vpt/f1 \& Vpt/f2, Fig. 11 have a primary current of the transformer Ipt/f1 \& Ipt/f2, Fig. $12 \& 13$ Shows secondary voltage of the transformer and current \& Fig. $14 \& 15$ shows Load voltage and load current.

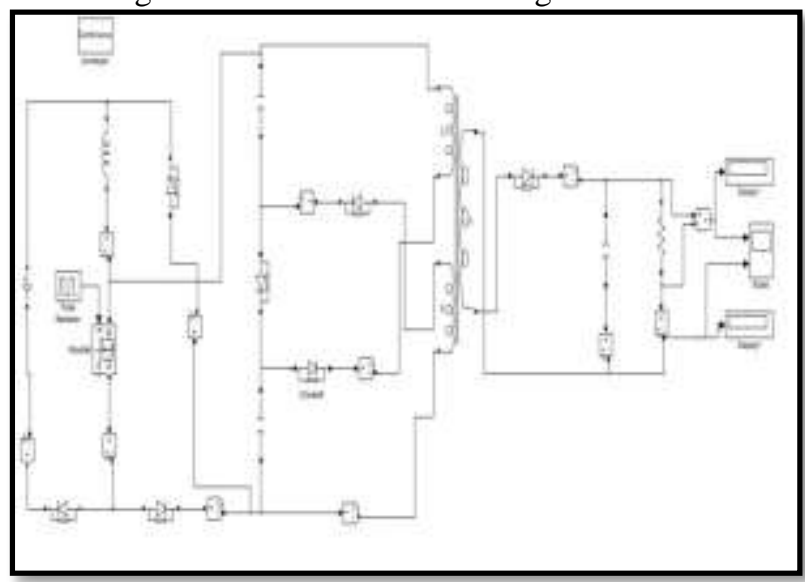

Fig. 3 MATLAB simulated Model 


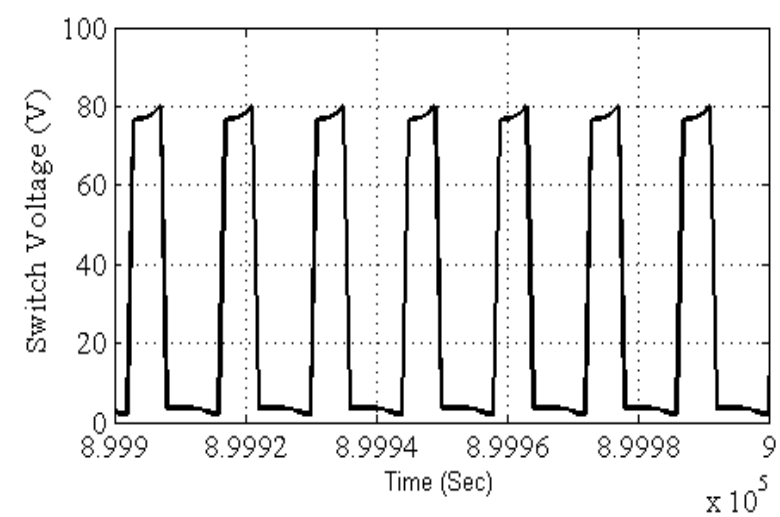

Fig. 4: Switch Voltage

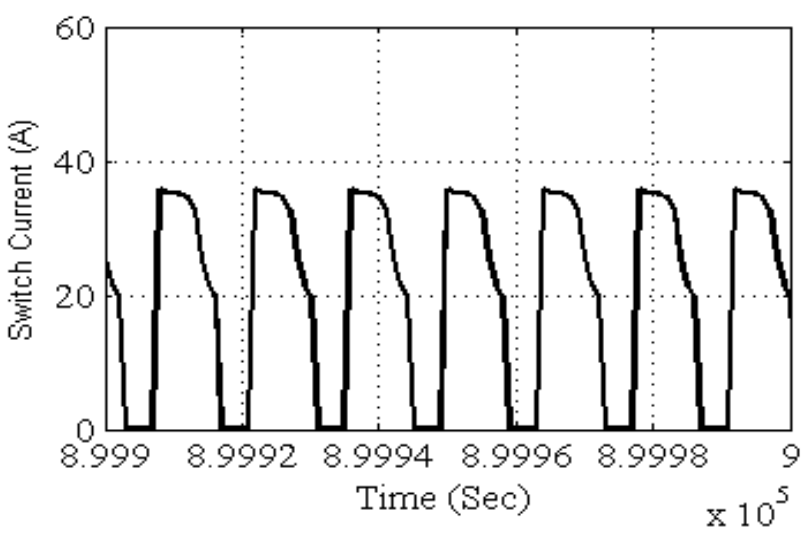

Fig. 5: Switch Current

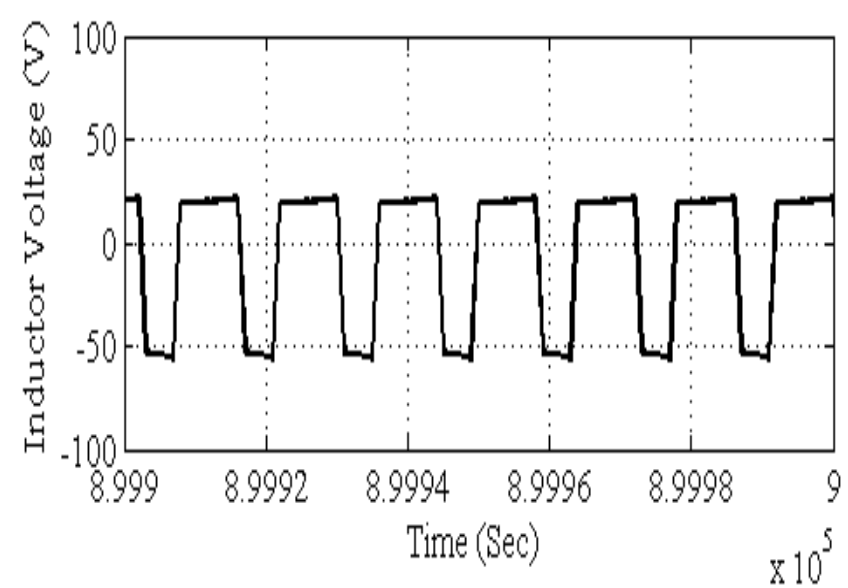

Fig. 6: Inductor Voltage

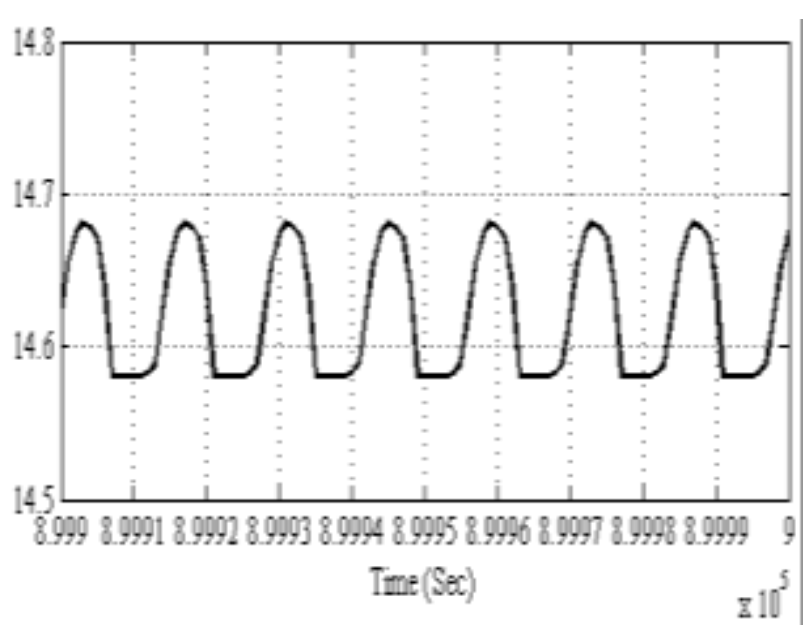

Fig. 7: Inductor Current

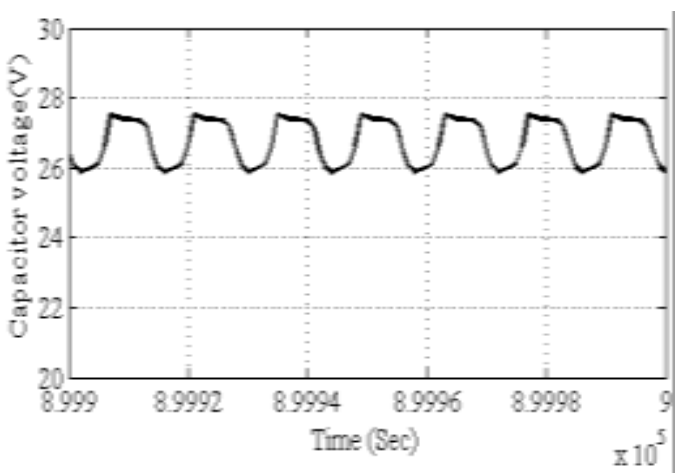

Fig. 8: Capacitor Voltages

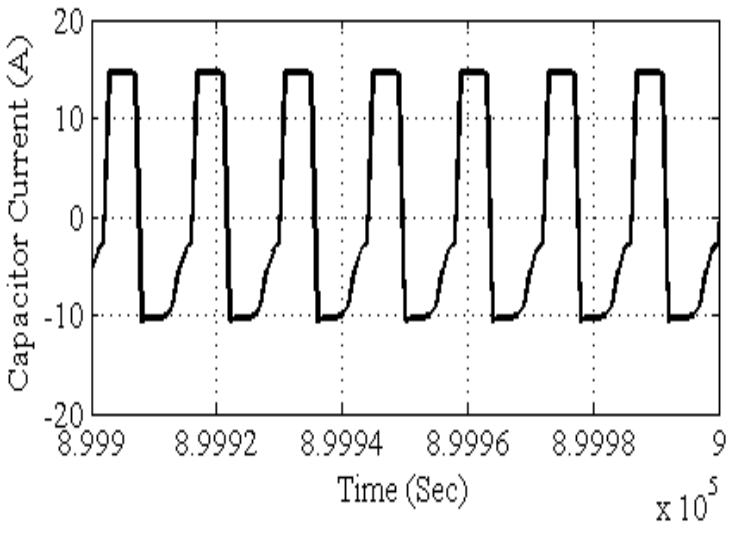

Fig. 9: Capacitor Currents

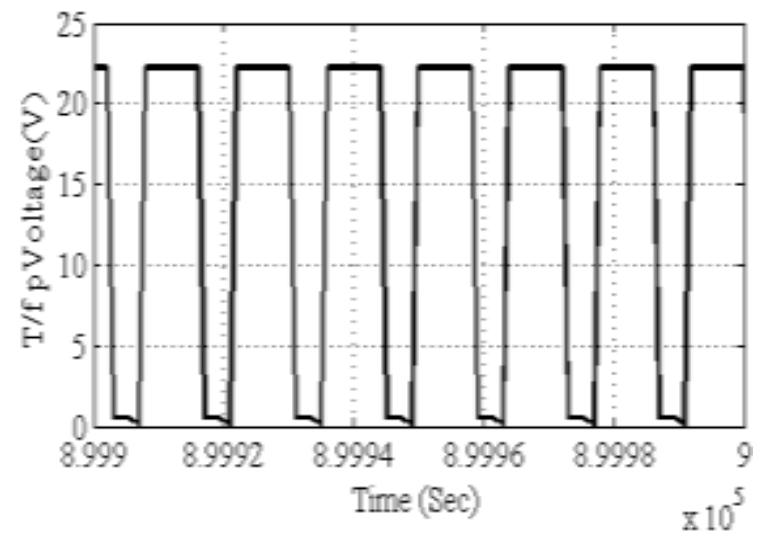

Fig. 10: $1^{\text {st }}$ winding Voltage of Transformer

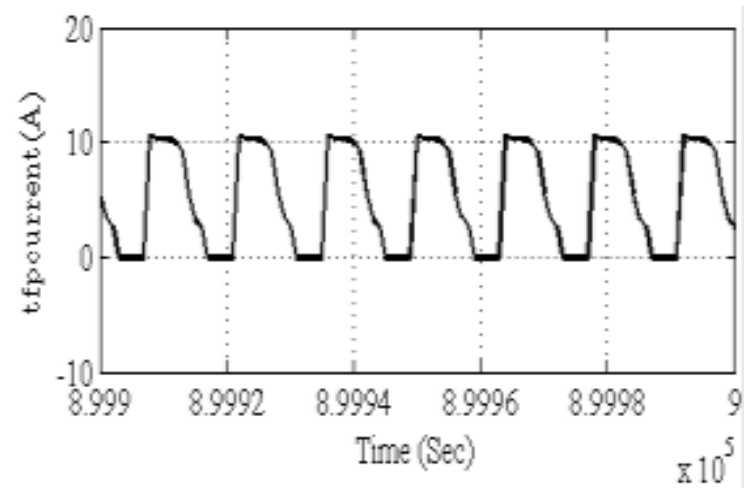

Fig. 11: $1^{\text {st }}$ winding Current of Transformer

Published By:

Blue Eyes Intelligence Engineering

\& Sciences Publication 


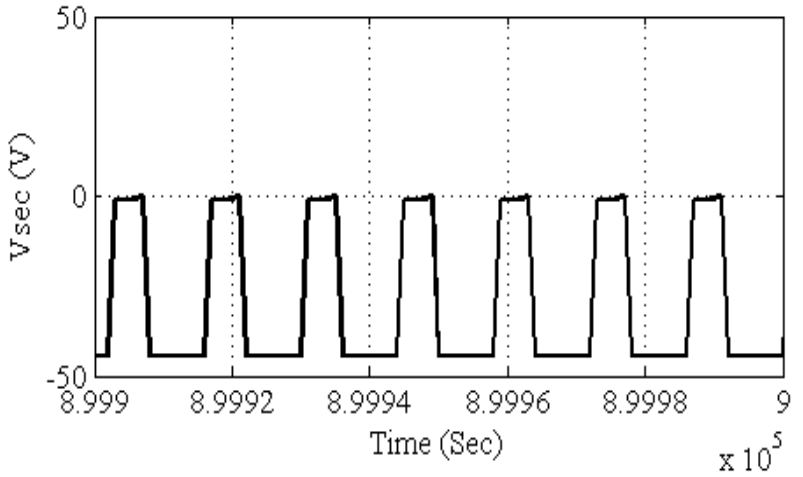

Fig. 12: Transformer Secondary Voltage

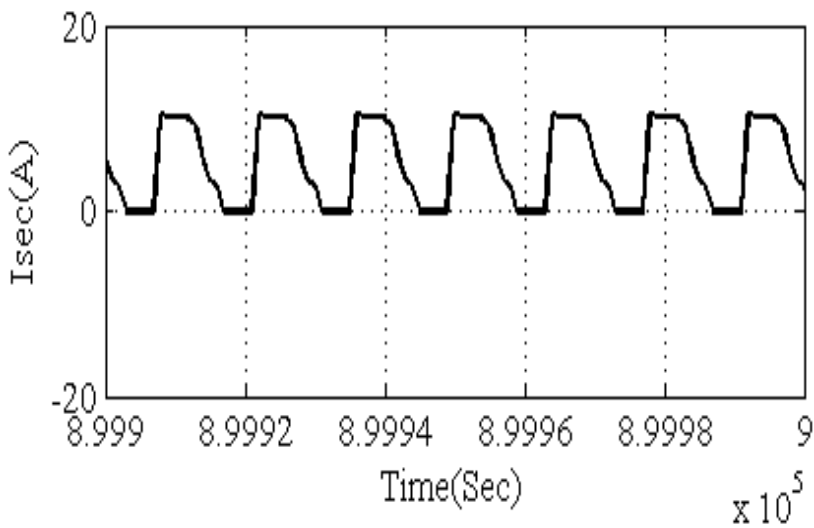

Fig. 13: Transformer Secondary Current

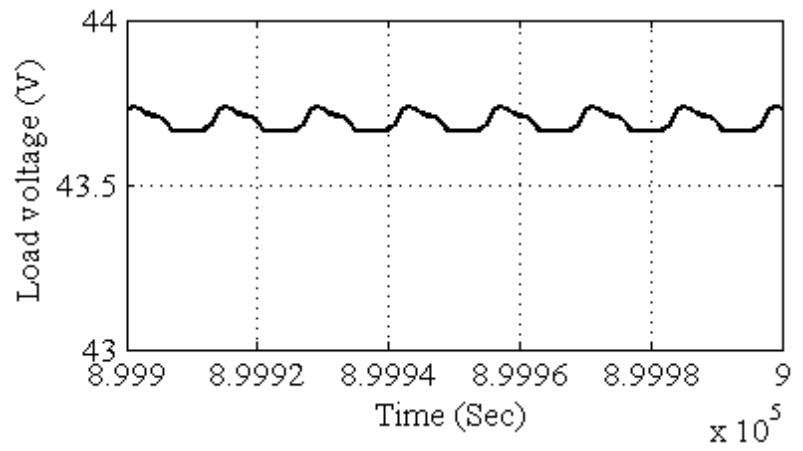

Fig. 14: Output Voltage

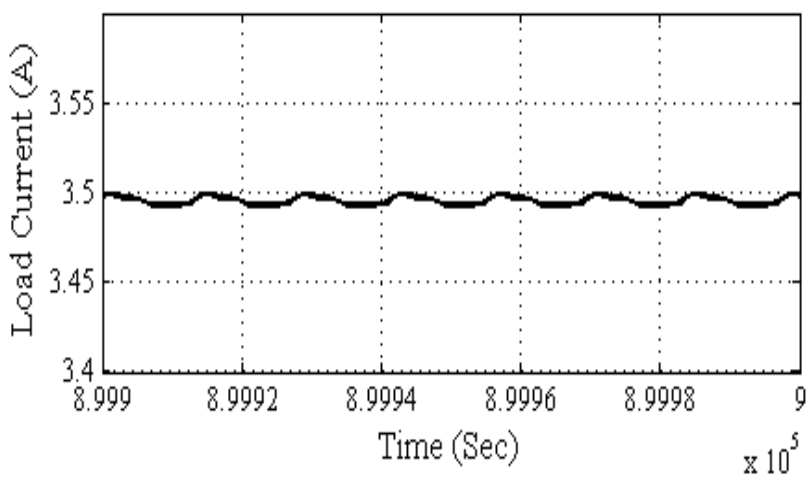

Fig. 15: Output Current

\section{EXPERIMENTAL RESULTS}

The Home based kit with the Experimental results for Open Loop Control is shown with $24 \mathrm{~V}$ input Voltage duty cycle is $67 \%$. Fig.(16) Shows the hardware setup. Fig. (17 \& $18)$ is Inductor voltage and current, fig. (19 \&20) shows the
Capacitor Voltages \& Currents, fig.(21 \& 22) shows the transformer primary and secondary voltages, fig. (23) is transformer current, fig.(24) shows switch current and fig. (25) shows the output voltage and current waveforms.

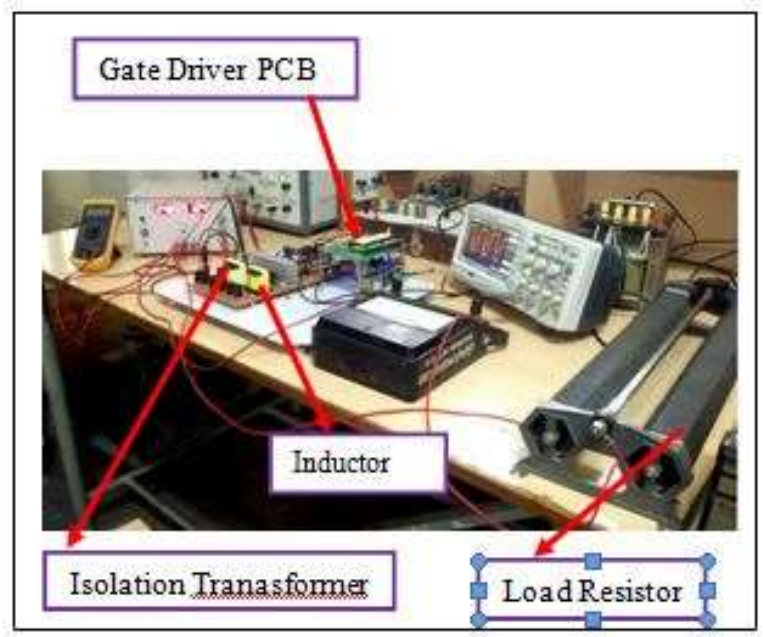

Fig. 16 - Hardware Setup of IBBSPFC

The Components used in the hard ware setup is Protection circuit, gate pulse circuit, reset circuit, inductor, capacitors, diodes, transformer, switch with heat sink.

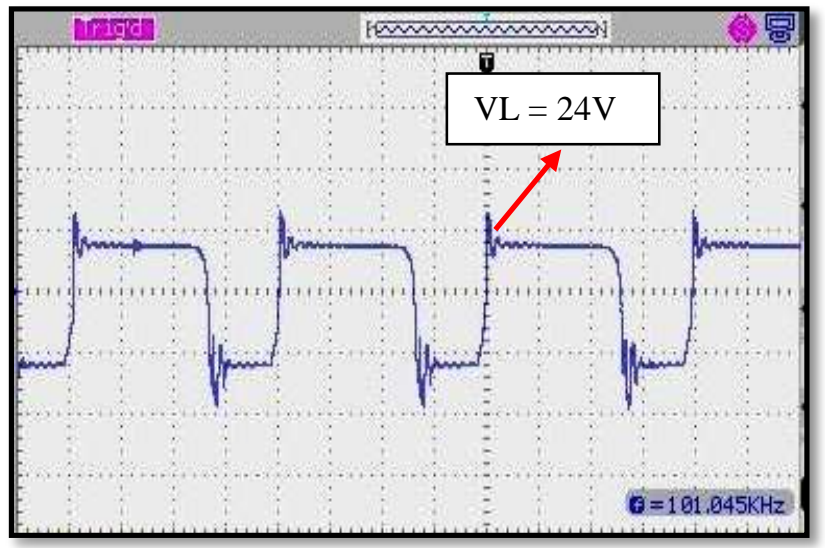

Fig. 17 - Inductor Voltage

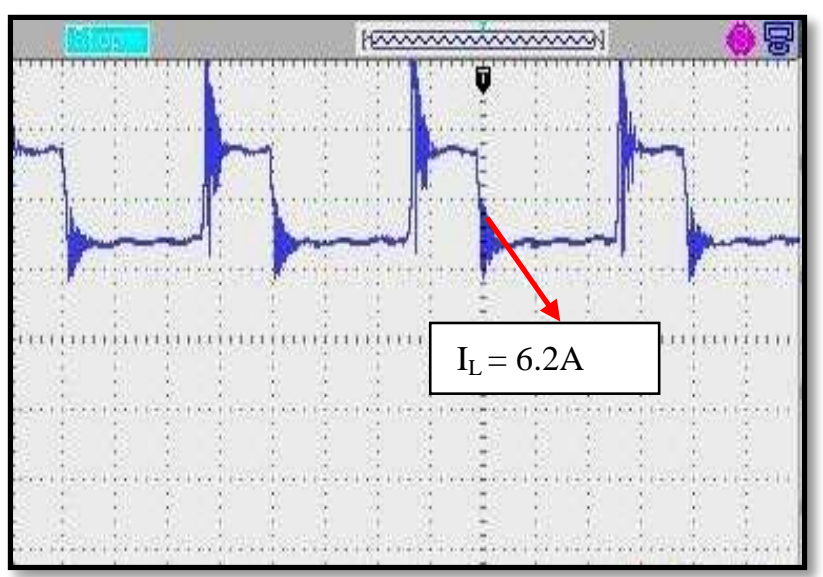

Fig. 18 - Inductor Current

Published By:

Blue Eyes Intelligence Engineering \& Sciences Publication 


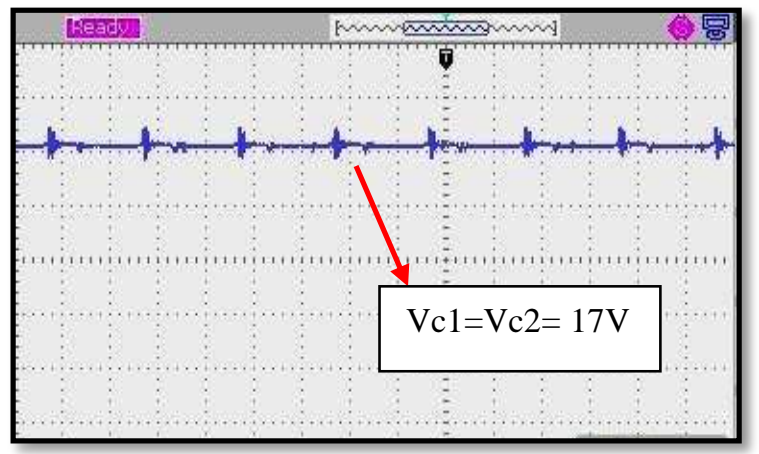

Fig.19 - Capacitor Voltages $V c_{1}$ and $V c_{2}$

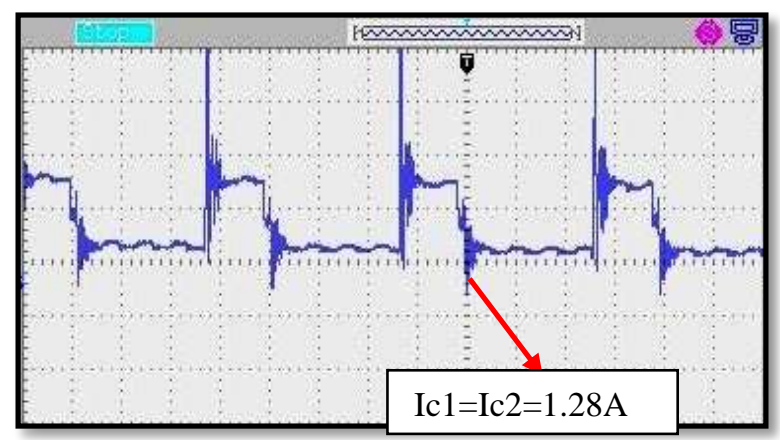

Fig.20 - Capacitor Currents $I c_{1}$ and $I c_{2}$

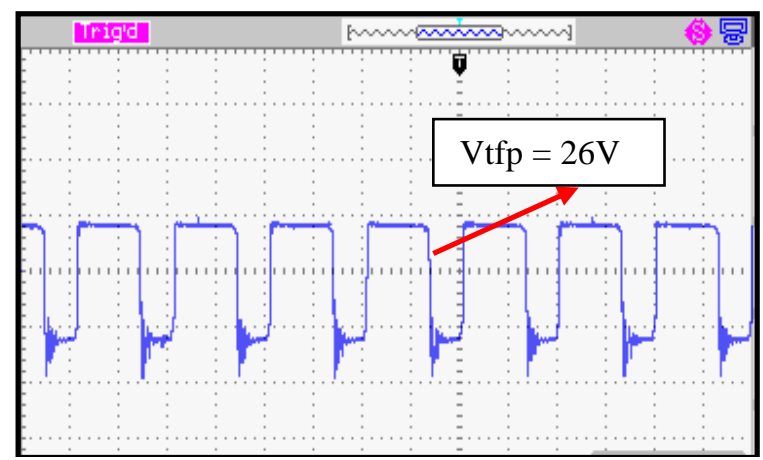

Fig.21 - Transformer primary voltages $\mathrm{Vt}_{1}$ and $\mathrm{Vt}_{2}$

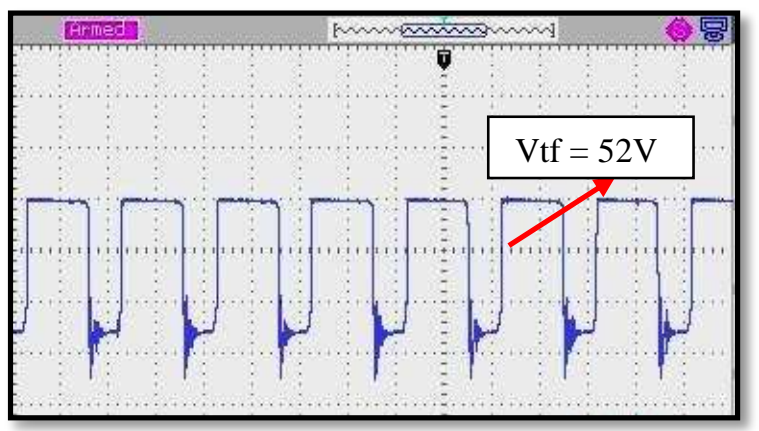

Fig.22 - Transformer Secondary voltage $V_{\text {Sec }}$

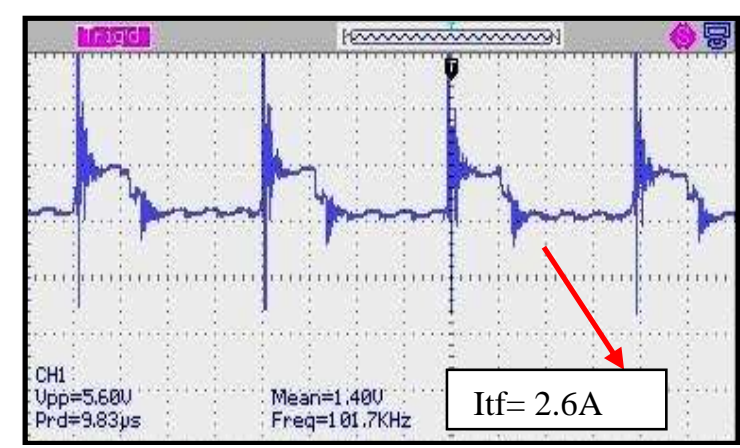

Fig.23 - Transformer Primary Currents

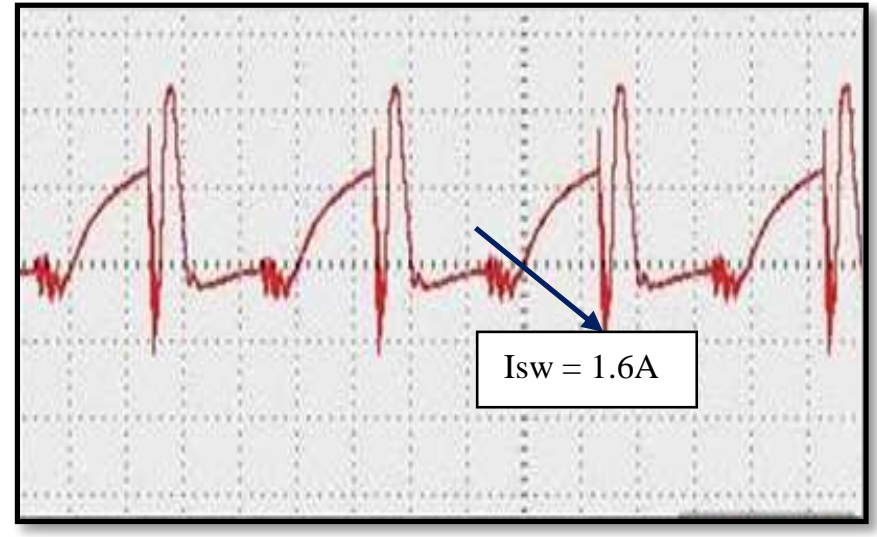

Fig.24 - Switch Current

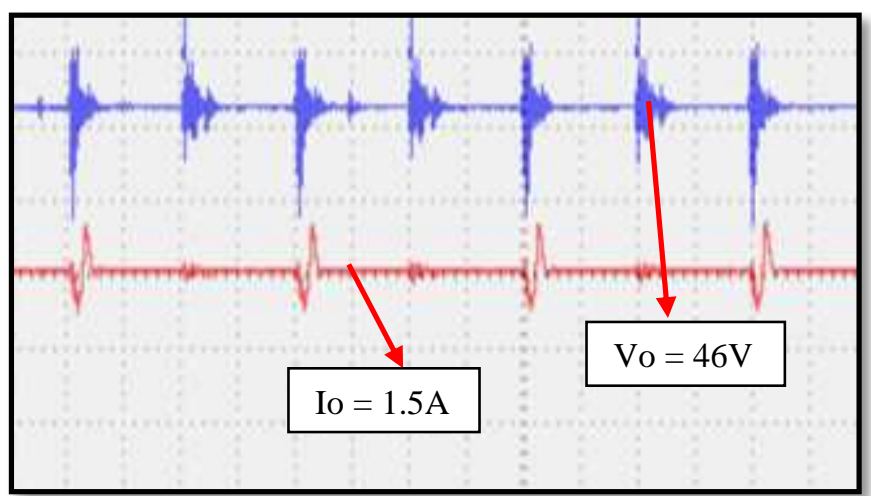

Fig.25 - Output Voltage and Current

\section{COMPARISON TABLE}

Table 1 shows the comparison of simulation values and practical values with the voltage and current.

\begin{tabular}{|c|c|c|c|c|}
\hline \multirow{2}{*}{ Parameter } & \multicolumn{2}{|c|}{ Theoretical Value } & \multicolumn{2}{c|}{ Practical Value } \\
\cline { 2 - 5 } & $\begin{array}{c}\text { Voltage } \\
\text { [V] }\end{array}$ & $\begin{array}{c}\text { Current } \\
{[\mathbf{A}]}\end{array}$ & $\begin{array}{c}\text { Voltage } \\
\text { [V] }\end{array}$ & $\begin{array}{c}\text { Current } \\
{[\mathbf{A}]}\end{array}$ \\
\hline Input Side & 24 & 4.16 & 24 & 3.24 \\
\hline Output side & 49 & 1.83 & 46 & 1.5 \\
\hline $\begin{array}{c}\text { Inductor } \\
\text { Capacitor }\end{array}$ & 24 & 6.3 & 22.58 & 6.249 \\
\hline $\begin{array}{c}\text { Transformer } \\
\text { 1 \& 2 }\end{array}$ & 25 & 1.26 & 26 & 2.64 \\
\hline
\end{tabular}

Table 1Comparison of theoretical and practical values

Table 2 shows the specifications of the hardware kit with the parameters used in the hardware prototype. 


\begin{tabular}{|c|c|}
\hline Parameter & $\begin{array}{c}\text { Specification \& } \\
\text { Rating }\end{array}$ \\
\hline Inductor & $100 \mathrm{KHz}, 10 \mu \mathrm{H}, 8 \mathrm{~A}$ \\
\hline Capacitor & $1000 \mu \mathrm{F}, 50 \mathrm{~V}$ \\
\hline $\begin{array}{c}\text { Fast Recovery } \\
\text { Diode }\end{array}$ & MUR3060 $-600 \mathrm{~V}, 30 \mathrm{~A}$ \\
\hline $\begin{array}{c}\text { Transformer } \\
\text { MOSFET }\end{array}$ & $1: 1,25 / 25 \mathrm{~V}$ \\
\hline IRF460 $-500 \mathrm{~V}, 21 \mathrm{~A}$ \\
\hline
\end{tabular}

Table 2 Components specification

\section{CONCLUSION}

The devise procedure with the circuit arrangement of IBBSPFC has been presented. The efficiency of the converter is nearly $90 \%$, Advantage of this converter is only single switch is used so that switching stress is reduced, it has high transfer capability of power and reliability. The proposed circuit is simulated with supply input voltage of $24 \mathrm{~V}$ and voltage output of $50 \mathrm{~V}$ with $100 \mathrm{~W}$ power and switching frequency of $100 \mathrm{KHz}$.

This converter can be given to the renewable sources to get the voltage low or high to the inverter or to the loads. This paper can be extended further with solar PV cells with MPPT algorithm and the output of the converter can be taken to multi-loads from the secondary sides of the isolation transformer.

\section{REFERENCES}

1. Rong-Jong Wai, Wen-Hung Wang, and Chung-You Lin "High-Performance Stand-Alone Photovoltaic Generation System," IEEE Trans. on industrial electronics, vol. 55, NO. 1, 2008, Jan.

2. Kuei-Hsiang Chao, Min-Sen Yang, "High step-up interleaved converter with soft - switching using a single auxiliary switch for a fuel cell system, " IEEE Trans. IET Power Electron., 2014, Vol. 7, Iss. 11, pp. 2704-2716.

3. R. D. Middlebrook, fellow IEEE, "Tranformerless Dc-DC converter with large conversion ratios," IEEE Trans. on power electronics, vol. 3, NO. 4, 1998, Oct.

4. M.H. Taghvaee, M.A.M. Radzi, S.M. Moosavain, H Hizam, M. H Marhaban, "A current and future study of non-isolated dc-dc converters for PV application," ELSEVIER Renewable and Sustainable Energy Reviews, 17 (2013) 216-227.

5. Portillo Quesada, Daniel, "Design and construction of an isolated Dc-Dc fly-back converter for solar MPPT" IDEALS publication, 2018,05.

6. Nor Hanisah Baharudin, Tunku Muhammad Nizar Tunku Mansur, Fariruz Abdul Hamid, Rosnazri Ali, Muhammad Irwanto Misrun. "Topology of DC-DC Converter in Solar PV Applications" Indonesian Journal of Electrical Engineering and computer Science Vol.8, No.2, November 2017.

7. L.M Redondo, and J.F. Silva, "Flyback versus forward switching power supply topologies for unipolar pulsed power applications", Plasma Science, IEEE Trans. on,Vol.37, No.1 PP.171-178, 2009.

8. Pooya Davari, Firuz Zare and Arindam Ghosh "Parallel and series configurations of flyback converter for power applications," School of Electrical Engineering and Computer Science Queensland University of Technology Brisbane, Australia.

9. Sravan Kumar S.L.V, Ravi Sankar Reddy N, Vijay
Kumar. M "Voltage mode control of integrated boost series parallel fly-back converter for energy storage applications," 1st international conference on power engineering computing and control PECCON-2017,2-4 March 2017,VIT University, Chennai Campus. 